\title{
Semantic Priming in Broca's Aphasics at a Short SOA: No Support for an Automatic Access Deficit
}

\author{
Peter Hagoort \\ Max Planck Institute for Psycholinguistics, Nijmegen, The Netherlands
}

\begin{abstract}
This study tests the recent claim that Broca's aphasics are impaired in automatic lexical access, including the retrieval of word meaning. Subjects are required to perform a lexical decision on visually presented prime target pairs. Half of the word targets are preceded by a related word, half by an unrelated word. Primes and targets are presented with a long stimulus-onset-asynchrony (SOA) of $1400 \mathrm{msec}$ and with a short SOA of $300 \mathrm{msec}$. Normal priming effects are observed in Broca's aphasics for both SOAs. This result is discussed in the context of the claim that Broca's aphasics suffer from an impairment in the automatic access of lexical-semantic information. It is argued that none of the current priming studies provides evidence supporting this claim, since with short SOAs priming effects have been reliably obtained in Broca's aphasics. The results are more compatible with the claim that in many Broca's aphasics the functional locus of their comprehension deficit is at the level of postlexical integration processes. () 1997 Academic Press
\end{abstract}

\section{INTRODUCTION}

Once upon a time, lexical-semantic deficits were believed to be one of the dimensions that clearly separated the symptom space of Wernicke's and Broca's aphasics. Studies in which subjects were required to explicitly judge semantic relations obtained evidence for severe disruptions of lexical-semantic processing in Wernicke's aphasics (e.g., Goodglass \& Baker, 1976; Grober, Perecman, Kellar, \& Brown, 1980; Whitehouse, Caramazza, \& Zurif, 1978; Zurif, Caramazza, Myerson, \& Galvin, 1974). Performance of patients with Broca's aphasia in these studies, however, was close to normal. This led to the claim that in Wernicke's aphasia the semantic lexicon was

Address correspondence and reprint requests to Peter Hagoort, Max Planck Institute for Psycholinguistics, P.O. Box 310, NL-6500 AH Nijmegen, The Netherlands. Fax: ()-31-243521213; E-mail: peha@mpi.nl.

I thank Nancy Schuurman for her assistance in testing the subjects, and Pienie Zwitserlood and four anonymous reviewers for their comments on an earlier version of this article. 
structurally affected, whereas in Broca's aphasia it was largely intact (Grober et al., 1980).

Today, we no longer live in a world with such clear divisions. A number of studies using a semantic priming paradigm in which patients were asked to make a lexical decision on the targets (Blumstein, Milberg, \& Shrier, 1982; Chenery, Ingram, \& Murdoch, 1990; Friedman, Glosser, \& Diamond, 1988; Hagoort, 1993; Katz, 1988; Milberg \& Blumstein, 1981; Milberg, Blumstein, \& Dworetzky, 1987; Ostrin \& Tyler, 1993; Prather, Zurif, Stern, \& Rosen, 1992), cast serious doubts on the earlier account of lexicalsemantic deficits, for two reasons. First, despite significantly longer response latencies, Wernicke's aphasics consistently showed the same pattern of results as the normal control subjects; that is, both the control subjects and the Wernicke patients needed less time to recognize the target as a word when it was preceded by an associatively related word (Blumstein et al., 1982; Friedman et al., 1988; Hagoort, 1993; Milberg et al., 1987). Second, surprisingly enough, Broca's aphasics had a less stable pattern of performance, in that some studies reported no priming effects in these patients (Milberg \& Blumstein, 1981; Milberg et al., 1987). In other studies, however, Broca patients showed the expected priming effect (Blumstein et al., 1982; Hagoort, 1993; Katz, 1988; Ostrin \& Tyler, 1993).

Two general conclusions have been drawn from these results. First, for many aphasic patients lexical-semantic deficits are not due to a loss of "the integrity of the stored lexical knowledge base'" (Milberg et al., 1987, p. 139), but rather relate to a problem in the processing operations on lexical-semantic information. Thus, Wernicke's aphasics seem to be able to automatically retrieve word meaning, but fail in further exploiting this information under explicit memory conditions (cf. Graf \& Mandler, 1984; Hagoort, 1993). The second conclusion that has been drawn is that Broca's aphasics might suffer from an impairment in the automatic routines to access lexical-semantic information (Milberg et al., 1987).

The claim that Broca's aphasics are impaired in the automatic retrieval of word meaning has not gone unnoticed within and outside the neurolinguistic literature (e.g., Petersen \& Fiez, 1993). It is exactly this claim that serves as the focus of the current study. Despite their strong resonance, both the empirical basis and the theoretical basis of this claim for an automatic access deficit in Broca's aphasics are actually rather weak. So far, the majority of priming studies have found largely normal priming results in patients with Broca's aphasia (Blumstein et al., 1982; Hagoort, 1993; Katz, 1988; Milberg, Blumstein, \& Dworetzky, 1988; Ostrin \& Tyler, 1993). Only two studies (Milberg \& Blumstein, 1981; Milberg et al., 1987) did not obtain priming effects in these patients.

The theoretical weakness of the claim resides in the implicit assumption that word priming studies only or mainly tap automatic processing of lexical information, including word meaning. As I have argued elsewhere (Hagoort, 
1993), there is convincing evidence (Balota \& Chumbley, 1984; De Groot, 1984; De Groot, Thomassen, \& Hudson, 1986; Keefe \& Neely, 1990; Neely, 1977, 1991; Neely \& Keefe, 1989; Neely, Keefe, \& Ross, 1989; Seidenberg, Waters, Sanders, \& Langer, 1984) that priming effects can be attributed to both automatic and more controlled priming mechanisms.

To date, the most articulated analysis of the different priming mechanisms is that of Neely and Keefe (1989). They argue that three different mechanisms are required to account for the full spectrum of priming effects observed in reaction time tasks. Only one of these mechanisms is claimed to be automatic; the remaining two are forms of controlled processing.

The first mechanism is the automatic spread of activation. It assumes that strong (or direct) links exist between semantically and associatively related nodes in the lexical-semantic network (cf. Collins \& Loftus, 1975). On presentation of a word, the corresponding lexical-semantic node is activated, and this activation spreads along the paths in the network to nodes representing words that are related in meaning. As a consequence, the activated nodes representing related word targets need less time for subsequent processing.

The second mechanism is expectancy-induced priming. Subjects can generate an expectancy set on the basis of the information contained by the prime. This expectancy set consists of words that are potential targets. If the target is a member of this set, it will be recognized more quickly. If it is not, recognition will be slowed down. The circumstances which bring about expectancy-induced priming are most likely specific to the prime-target priming paradigm, and it has therefore been argued that this particular form of priming does not reflect the standard operations of lexical access and integration during language comprehension (cf. De Groot, 1984; Neely, 1991).

The third mechanism is semantic matching, again a controlled process. In a lexical decision task it is assumed that subjects match primes with targets and bias their decision according to the results of this matching process. The detection of a relationship between primes and targets leads to a bias to respond "yes." If no relation is detected, then there is a bias to respond "no." Therefore the required yes response will be inhibited. Although Neely and Keefe (1989) posit that the effects of semantic matching are particularly salient in priming patterns obtained with the lexical decision task, it has been argued that semantic matching processes play a role in everyday language comprehension (Brown \& Hagoort, 1993; De Groot, 1984; Henderson, 1982; Neely, 1991).

A number of factors determine whether automatic or controlled priming mechanisms are the main contributors to the overall priming effect. One of these factors is the stimulus-onset-asynchrony (SOA) between prime and target. Automatic priming is mainly tapped at short SOAs, whereas controlled priming mechanisms are responsible for priming effects observed at long SOAs (e.g., De Groot, 1984; Neely, 1977, 1991).

The studies in which no priming effects were observed in the Broca's 
aphasics used relatively long SOAs between primes and targets. An extension of the study by Milberg et al. (1987), including a short interval between auditorily presented primes and targets, resulted in significant priming effects at short intervals for a group of Broca's aphasics (Hagoort, 1993). In the same study, these Broca's aphasics no longer showed a significant priming effect when the interval between primes and targets was increased to 1250 msec. Milberg and Blumstein (1981) used a visual presentation of primes and targets with an SOA of $2000 \mathrm{msec}$. This SOA is clearly much longer than SOAs that are assumed to mainly tap automatic lexical processing. The available empirical evidence from priming studies with Broca's aphasics, therefore, is insufficient to unequivocally draw the conclusion that these patients are impaired in automatically accessing the mental lexicon.

To further test the nature of lexical processing impairments in Broca's aphasics, in the current study the SOA between visually presented primes and targets was varied. In a first experiment a long SOA between primes and targets was used to test for possible impairments in controlled priming mechanisms. The second experiment used a short SOA to test for deficits in automatic priming.

\section{EXPERIMENT 1}

\section{Method}

Subjects. The subjects in this experiment were 13 aphasic patients and 16 elderly subjects from the subject pool of the Max Planck Institute for Psycholinguistics. The elderly subjects served as the normal control group. They were paid for their participation. The normal controls were approximately matched with the aphasic patients in age and education. The mean age of the control subjects was 60 (range: 52-73); the mean age of the aphasic patients was 55 . All aphasic patients were administered the Dutch version of the Aachen Aphasia Test (AAT) (Graetz, de Bleser, Willmes, \& Heeschen, 1991). Patients were diagnosed by aphasia type both on the basis of their AAT results and on the basis of a transcribed sample of their spontaneous speech. The characteristics of the spontaneous speech were judged by three staff members of the Aphasia Project at the Max Planck Institute. All aphasic patients in this study were unanimously diagnosed as Broca's aphasics. Apart from two patients, all Broca's aphasics had as etiology a left-hemisphere CVA, with frontal lobe involvement in patients for whom adequate CT information was available. Table 1 shows a summary of the patients' age, gender, scores on the Token Test, and performance on the AAT subtest on comprehension.

Materials. The materials in this study were taken from De Groot $(1983,1984)$. The stimuli consisted of visually presented pairs of letter strings. The first letter string was always a Dutch word serving as the prime. The second letter string served as the target and could be either a word or a nonword. Half of the targets were words; half were nonwords. Nonwords were orthographically legal strings in Dutch. They were derived from Dutch nouns by adding or deleting one or two letters.

The 80 critical word targets were Dutch nouns, adjectives, or verbs. All word targets had either one or two syllables, and varied in length between three and eight letters. Half of the targets were associatively related to the prime; the other half were unrelated in meaning to the preceding word prime. Targets in the related and unrelated condition were closely matched in length and frequency. The frequencies were established on the basis of Dutch frequency norms for a corpus of 720,000 words (Uit den Boogaart, 1975). The related word targets had 
TABLE 1

Individual Patient History and Results on Subtests of the AAT

\begin{tabular}{llccrr}
\hline Patient & Etiology & Age & Sex & $\begin{array}{r}\text { Token test } \\
\text { of errors }\end{array}$ & Comprehension \\
\hline A.N. & CVA & 60 & M & $5 / 50$ & $104 / 120$ \\
H.T. & CVA & 55 & M & $39 / 50$ & $73 / 120$ \\
L.V. & CVA & 56 & F & $20 / 50$ & $82 / 120$ \\
G.M. & CVA & 54 & M & $12 / 50$ & $97 / 120$ \\
H.O. & CVA & 61 & F & $12 / 50$ & $98 / 120$ \\
N.R. & CVA & 64 & M & $50 / 50$ & $90 / 120$ \\
G.S. & CVA & 72 & M & $13 / 50$ & $102 / 120$ \\
H.U. & CVA & 62 & M & $24 / 50$ & $102 / 120$ \\
G.V. & CVA & 64 & M & $28 / 50$ & $76 / 120$ \\
H.M. & CVA & 42 & M & $10 / 50$ & $114 / 120$ \\
J.Th. & Angioblast. & 70 & F & $32 / 50$ & $72 / 120$ \\
S.W. & Meningitis & 25 & M & $34 / 50$ & $85 / 120$ \\
M.L. & CVA & 35 & F & $31 / 50$ & \\
\hline
\end{tabular}

Note. Severity of the aphasia as indicated by the Token Test: no/minimal disorder (0-6); light (7-23); middle (24-40); severe (41-50). Severity of the comprehension disorder as indicated by the AAT subtest Comprehension (includes word and sentence comprehension in auditory and visual modalities): no/minimal (108-120); light (89-107); middle (46-88); severe (0-45). Ranges of severity are based on the norms for the Dutch version of the AAT.

a mean frequency of 59 (SD 63); the unrelated targets had a mean frequency of 57 (SD 78). The mean association strength of the related pairs was obtained from published association norms established with a population of 100 students (De Groot, 1980) and is 47 (SD 22).

In addition to the 80 word pairs and the 80 pairs with nonword targets, a set of 26 practice items was constructed to familiarize the subjects with the task. The list of prime target pairs started with an additional 8 start-up items. The ratio of words and nonwords, related and unrelated targets in practice, and start-up items was the same as for the experimental items.

Apparatus. The apparatus for the experiment consisted of a high-resolution PC monitor, a Miro GD laboratory computer, and a response keyboard with a YES button and a NO button. Stimuli were centrally presented in a $8 \times 2-\mathrm{cm}$ window on the monitor, which was covered by a black nonreflecting shield. Primes were presented in lowercase letters, and targets in uppercase letters. Reaction times and type of response (yes/no) were stored directly with the aid of the computer. The time-out was set to $2 \mathrm{sec}$. Latencies longer than $2 \mathrm{sec}$ were automatically stored as missing values.

Procedure. The subjects were tested individually in sessions lasting approximately $30 \mathrm{~min}$. Subjects were seated in a dimly illuminated room, diagonally opposite the experimenter, with the monitor and the keyboard placed in front of them. Viewing distance was approximately $50 \mathrm{~cm}$, and the stimuli subtended a vertical visual angle of $3^{\circ}$.

Subjects were told that they would see pairs of letter-strings either ending with a real Dutch word or ending with a nonword. They were told to respond to the second letter-string as quickly and accurately as possible, indicating whether it was a word by pressing the YES button or a nonword by pressing the NO button. After the familiarization procedure, the subjects were asked to increase the speed of responding without losing accuracy. The emphasis on speed served the purpose of making the task as on-line as possible. No further feedback was given during the test session.

Normal subjects were required to press the YES button with the preferred hand. Due to the 
TABLE 2

Mean Reaction Times (in msec) of Control Subjects $(n=16)$ and Broca's Aphasics $(n=10)$ for Related and Unrelated Word Targets

\begin{tabular}{lccc}
\hline SOA $=1400$ msec & Related & Unrelated & Unr.-rel. \\
\hline Normal controls & 637 & 691 & 54 \\
Broca's aphasics & 746 & 812 & 66 \\
\hline
\end{tabular}

occurrence of hemiparesis or hemiplegia in a number of Broca patients, all patients were required to respond with their left index finger. Patients were instructed to place their left index finger on the YES button and to move their finger to the NO button if they wanted to give a no response. This was done to speed up the reaction times for the more important yes responses and to avoid an increase in the error variance as a result of movements to be made from a starting position between the two buttons (cf. Hagoort, 1993).

Primes and targets both were presented for a period of $1000 \mathrm{msec}$. The SOA between primes and targets was $1400 \mathrm{msec}$. Target presentation was followed by a blank screen for $3 \mathrm{sec}$ before the next trial started.

\section{Results}

The results for the normal control subjects and the aphasic patients were analyzed separately. For the analyses on the RT data, errors and missing values were replaced for every subject by his/her mean per condition. Repeated Measures Analyses of Variance were performed on RT data and error data, with Subjects and Priming Condition (related, unrelated) completely crossed. Since the error data supported the RT data, only the analyses for the RT data will be reported.

The normal control subjects made errors on $3.1 \%$ of the word targets ( $2.7 \%$ in the related condition, $3.6 \%$ in the unrelated condition). The ANOVA on the latency data of the normal controls yielded a significant effect of Priming Condition $[F(1,15)=89.7, p<.0001]$. Lexical decision latencies for related targets were on average $54 \mathrm{msec}$ faster than for unrelated targets (see Table 2). Results for the individual subjects are given in the Appendix.

Two patients had relatively high error scores on the word targets $(26.3 \%$ and $21.5 \%$ ). Only one of the patients had a large number of time-outs on the word targets $(41.3 \%)$. The data of these three patients were therefore not further analyzed. They are, however, reported in the Appendix. The remaining 10 Broca's aphasics had a mean error score of $3.8 \%$ on the word targets $(2.8 \%$ in the related condition, and $4.8 \%$ in the unrelated condition). The ANOVA on the latency data of these 10 patients resulted in a significant effect of Priming Condition $[F(1,9)=10.7, p<.01]$. Patients were on average $66 \mathrm{msec}$ faster in the related than in the unrelated condition. Individual patient data are summarized in the Appendix. All aphasic patients but one showed faster RTs in the related than in the unrelated condition. 


\section{Discussion}

The results of this first experiment are very clear-cut. Both the normal controls and the Broca's aphasics showed reliable priming effects at an SOA of $1400 \mathrm{msec}$ between primes and targets. Moreover, 12 of the 13 Broca's aphasics showed an effect in the expected direction (see the Appendix). Although the SOA in this experiment is shorter than the SOA in the Milberg and Blumstein (1981) study, it is still long enough for controlled priming mechanisms to influence the overall priming results. The question therefore remains whether the Broca's aphasics tested in Experiment 1 still show a priming effect when the SOA between primes and targets is drastically reduced. Priming effects obtained with very short SOAs are usually assumed to rely more on automatic priming mechanisms, such as the automatic spreading of activation between related nodes in the semantic lexicon (Collins \& Loftus, 1975), than on controlled priming mechanisms (cf. Neely, 1991). The second experiment was performed to test whether in the same patients priming effects were still observed at a short SOA. In this experiment the same materials were presented with an SOA of only $300 \mathrm{msec}$ between primes and targets.

\section{EXPERIMENT 2}

\section{Method}

Subjects. The normal controls were 16 elderly subjects who had not participated in Experiment 1 . They were paid for their participation. These subjects were approximately matched with the aphasic patients in age and education. The mean age of the control subjects was 60 (range: 48-67). Ten of the Broca's aphasics that participated in Experiment 1 were also tested in this experiment. The three patients with high error scores or a large number of time-outs in the first experiment were excluded from participation. The time between testing patients in Experiment 1 and Experiment 2 was at least 3 weeks.

Procedure. The procedure was almost identical to the one in the first experiment. ${ }^{1}$ Primes were presented for $300 \mathrm{msec}$ immediately followed by the targets. In this way, the SOA between primes and targets was reduced from $1400 \mathrm{msec}$ in Experiment 1 to $300 \mathrm{msec}$ in this experiment. Targets were presented for $1000 \mathrm{msec}$. The interval between trials was $3 \mathrm{sec}$.

${ }^{1}$ The only difference was that a pretest preceded the actual experiment, to make sure that the Broca's aphasics were able to recognize the words under the rapid presentation conditions of the experiment. In this pretest 30 words were presented. Each word was presented for 300 $\mathrm{msec}$, and immediately followed by a row of hashmarks which stayed on the screen for 1000 msec. For each item of the pretest subjects were required to make a choice out of four alternatives, consisting of the target and three alternatives that had the same number of letters as the target word. Normal subjects made $2 \%$ errors on this pretest. The Broca's aphasics had an average error score of $6 \%$. This pretest therefore substantiates the claim that the rapid presentation conditions of the experiment did not prevent the aphasic patients from identifying the primes. 
TABLE 3

Mean Reaction Times (in msec) of Control Subjects $(n=16)$ and Broca's Aphasics $(n=10)$ for Related and Unrelated Word Targets

\begin{tabular}{lccc}
\hline SOA $=300 \mathrm{msec}$ & Related & Unrelated & Unr.-rel. \\
\hline Normal controls & 622 & 684 & 62 \\
Broca's aphasics & 724 & 796 & 72 \\
\hline
\end{tabular}

\section{Results}

The normal control subjects had a mean error score of $3.3 \%$ on the word targets $(2.2 \%$ in the related and $4.4 \%$ in the unrelated condition). The ANOVA on their lexical decision latencies resulted in a significant priming effect $[F(1,15)=98.9, p<.0001]$. Compared to the unrelated condition, RTs were on average $62 \mathrm{msec}$ faster in the related condition (see Table 3; see the Appendix for individual subject data).

On average, the Broca's aphasics made errors on $2.8 \%$ of the word targets (2.0\% in the related condition, $3.5 \%$ in the unrelated condition). The ANOVA on their latency data yielded a significant effect of Priming Condition $[F(1,9)=19.1, p<.005]$. The overall size of the priming effect was $72 \mathrm{msec}$. All patients but one showed a difference in the right direction (see the Appendix for individual patient data).

\section{GENERAL DISCUSSION}

Figure 1 summarizes the results for both SOAs and for both subject groups. The Broca's aphasics that were tested showed essentially the same priming effects as the normal control subjects, not only at a long SOA but also at a very short SOA between primes and targets. Moreover, this general pattern was seen in the large majority of patients.

The implication of these results for a precise account of lexical processing deficits in aphasic patients critically depends on whether or not the short SOA condition taps into processes related to automatic lexical access. Classically, SOAs of around $300 \mathrm{msec}$ have been claimed to mainly tap automatic spreading of activation within the semantic lexicon (cf. Neely, 1991, for an overview). However, a number of recent studies suggest that the picture might be more complicated (Balota, Black, \& Cheney, 1992; Shelton \& Martin, 1992). There is some evidence that even at short prime-target intervals priming observed for words presented in prime-target pairs might to a certain degree also depend upon controlled priming mechanisms (Shelton \& Martin, 1992). Moreover, the effects of automatic spreading of activation and strategic attentional processing are most likely not independent (Balota et al., 1992; Carr \& Dagenbach, 1990). Nevertheless, the relative contribution of automatic spreading of activation is generally assumed to be larger at short 




FIG. 1. Means of the lexical decision latencies as a function of priming condition and SOA, for both Broca's aphasics $(N=10)$ and their elderly controls $(N=16)$.

than at long SOAs, whereas the opposite holds for controlled priming mechanisms, such as expectancy generation and semantic matching (Neely \& Keefe, 1989).

Whatever the outcome of further studies will reveal about the priming mechanism(s) responsible for semantic priming at short SOAs, the consequences for the claim that Broca's aphasics suffer from a problem in automatically accessing lexical-semantic information remain more or less the same. If short SOAs mainly tap automatic lexical processing, the conclusion must be that this study and other studies (Hagoort, 1989; Milberg, Blumstein, Katz, Gershberg, \& Brown, 1995; Tyler, Ostrin, Cooke, \& Moss, 1995) do not provide any evidence that automatic lexical access in Broca's aphasics is impaired. The same conclusion holds for an account that attributes priming at short SOAs to controlled processing mechanisms. This is because if controlled processing explains priming at short SOAs, the claim of an automatic access deficit on the basis of previous priming studies has lost its empirical basis completely.

A modified account of an automatic access deficit is presented in Hagoort (1993) and more recently in Milberg et al. (1995). According to this proposal 
the spreading of activation through the lexical-semantic network occurs automatically. However, the level of activation is reduced due to a general reduction in the signal-to-noise ratio for lexical-semantic nodes, resulting in activation of lexical information at lower levels than in normals. This possibility cannot easily be discarded on the basis of the current evidence. However, a direct test of this modified account is still lacking.

The claim for a deficit in automatically accessing lexical-semantic information in Broca's aphasics has been largely based on their failure to show priming effects in a few priming studies. However, priming effects have been reported to be absent in Broca's aphasics, only when either the SOA between primes and targets was very long (Milberg \& Blumstein, 1981) or two primes were used instead of one in combination with relatively long SOAs (Hagoort, 1993; Milberg et al., 1987). ${ }^{2}$

Priming effects at relatively long intervals between primes and targets are more dependent on expectancy generation and postlexical semantic matching than on the automatic activation spreading triggered by lexical access (cf. Neely, 1991). So far, Broca's aphasics have shown no priming only under conditions which most likely strongly relied on nonautomatic priming mechanisms such as semantic matching. So far, the normal priming effect in Broca's aphasics was more affected when three instead of two words had to be matched for their semantic similarity (Hagoort, 1993; Milberg et al., 1987). The most likely reason is that semantic matching and the processing resources required for it to operate efficiently are more heavily taxed with an increase in the number of words that have to be matched for their semantic similarity. If Broca's aphasics are impaired in controlled priming mechanisms such as semantic matching, chances of finding absence of normal priming effects increase with the number of words that have to be matched. This might also account for the seeming discrepancy between the normal priming results at the long SOA in this study and the absence of priming at the longest interval in an earlier study (Hagoort, 1993) with in part the same patients. The current study with the visual presentation of word pairs was insufficiently taxing the semantic matching mechanism in this group of patients to observe its breakdown at the long SOA.

The results of this study in combination with all other results of priming

${ }^{2}$ Prather et al. (1992) report priming results from one nonfluent aphasic obtained in a listpriming paradigm, in which subjects have to perform a lexical decision on each word in the list. Priming was tested with a series of intervals between the items in the list. This patient showed a priming effect, but only at a longer interval than a group of elderly controls. The authors conclude that automatic lexical access was slowed down in this patient. However, at least two potential problems plague the authors' interpretation. The first one is that after removal of errors, statistical analyses in their crucial Experiment 1 are based on 41 RTs divided over six conditions, which is rather limited for a stable result. Second, no information is given on individual control subjects. This makes it hard to determine whether the patient falls within or outside the normal range (cf. Haarmann \& Kolk, 1991). 
studies with Broca patients suggest that language comprehension impairments of Broca's aphasics are, at least in part, functionally localized at the postlexical level of integrating word meaning into a representation of the word or sentence context (Marslen-Wilson, 1984). This integration process is more controlled than lexical access, in that it requires a context representation to be kept in working memory and a match of the target's lexical semantics against the semantic specifications of the context representation. Further support for an account in terms of impaired (or delayed) lexical integration processes in Broca's aphasics is obtained in studies testing the resolution of lexical ambiguity in sentence contexts (Hagoort, 1990; Swaab, Brown, \& Hagoort, 1995).

In normal language comprehension, integration of word meaning into an overall message-level representation is both mandatory and requires processing resources. The claim that the comprehension deficit in Broca's aphasics resides at this level is compatible with their overall good performance in off-line tasks that require the patient to make an explicit semantic judgment. In this latter case the patient is explicitly investing general processing resources in the maintenance and elaboration of the semantic aspects of the stimulus materials, in order to meet the task requirements (cf. Just \& Carpenter, 1992).

The results of the current study are compatible with previous studies using short intervals between primes and targets (Hagoort, 1989; Tyler et al., 1995) in showing that, so far, Broca's aphasics have always shown reliable priming at short SOAs. To the degree in which short SOAs tap more strongly into automatic than controlled lexical processing, this result is incompatible with the claim of a deficit in automatic lexical access (cf. Tyler et al., 1995, for a similar conclusion). To the degree in which even at short SOAs semantic priming relies largely on controlled processing, the conclusion must be that to date there is no empirical evidence from semantic priming studies in aphasic patients that can be taken to support the claim for an automatic lexical access deficit.

In conclusion, all current studies on associative and semantic priming in Broca's aphasics are compatible with the claim that these patients sometimes show a deficit in postlexical integration processes. However, the claim for an automatic access deficit of lexical-semantic information remains without empirical support. 


\section{APPENDIX}

Individual Subject Data for the Two Groups of Normal Controls (One for Each SOA) and the Group of Broca's Aphasics

\begin{tabular}{|c|c|c|c|c|c|c|}
\hline \multicolumn{4}{|c|}{$\mathrm{SOA}=300 \mathrm{msec}$} & \multicolumn{3}{|c|}{$\mathrm{SOA}=1400 \mathrm{msec}$} \\
\hline Subject & Related & Unrel. & Unr.-Rel. & Related & Unrel. & Unr.-Rel. \\
\hline \multicolumn{7}{|c|}{ Normal controls $(n=32)$} \\
\hline $17 / 01$ & 628 & 643 & 15 & 564 & 598 & 34 \\
\hline $18 / 02$ & 578 & 641 & 63 & 625 & 691 & 66 \\
\hline $19 / 03$ & 740 & 775 & 35 & 696 & 749 & 53 \\
\hline $20 / 04$ & 585 & 607 & 22 & 560 & 617 & 57 \\
\hline $21 / 05$ & 661 & 733 & 72 & 609 & 696 & 87 \\
\hline $22 / 06$ & 712 & 778 & 66 & 582 & 614 & 32 \\
\hline $23 / 07$ & 573 & 663 & 90 & 624 & 648 & 24 \\
\hline $24 / 08$ & 600 & 666 & 66 & 665 & 702 & 37 \\
\hline $25 / 09$ & 765 & 793 & 28 & 668 & 768 & 100 \\
\hline $26 / 10$ & 619 & 708 & 89 & 622 & 709 & 87 \\
\hline $27 / 11$ & 587 & 660 & 73 & 686 & 728 & 42 \\
\hline $28 / 12$ & 593 & 673 & 80 & 635 & 702 & 67 \\
\hline $29 / 13$ & 480 & 563 & 83 & 561 & 638 & 77 \\
\hline $30 / 14$ & 567 & 658 & 91 & 815 & 838 & 23 \\
\hline $31 / 15$ & 640 & 686 & 46 & 694 & 756 & 62 \\
\hline $32 / 16$ & 629 & 705 & 76 & 572 & 606 & 34 \\
\hline \multicolumn{7}{|c|}{ Broca's aphasics $(n=13)$} \\
\hline A.N. & 627 & 766 & 139 & 632 & 726 & 94 \\
\hline H.T. & - & - & - & 799 & 819 & 20 \\
\hline L.V. & 666 & 737 & 71 & 652 & 678 & 26 \\
\hline G.M. & 634 & 692 & 58 & 595 & 746 & 151 \\
\hline H.O. & 829 & 893 & 64 & 838 & 795 & -43 \\
\hline N.R. & 719 & 702 & -17 & 747 & 788 & 41 \\
\hline G.S. & - & - & - & 1301 & 1507 & 206 \\
\hline H.U. & 719 & 772 & 53 & 687 & 692 & 5 \\
\hline G.V. & 844 & 884 & 40 & 995 & 1087 & 92 \\
\hline H.M. & - & - & - & 934 & 1183 & 249 \\
\hline J.Th. & 798 & 967 & 169 & 884 & 1042 & 158 \\
\hline S.W. & 785 & 869 & 84 & 753 & 797 & 44 \\
\hline M.L. & 622 & 675 & 53 & 679 & 779 & 100 \\
\hline
\end{tabular}

\section{REFERENCES}

Balota, D. A., \& Chumbley, J. I. 1984. Are lexical decisions a good measure of lexical access? The role of word frequency in the neglected decision stage. Journal of Experimental Psychology: Human Perception and Performance, 10, 340-357.

Balota, D. A., Black, S. R., \& Cheney, M. 1992. Automatic and attentional priming in young and older adults: Reevaluation of the two-process model. Journal of Experimental Psychology: Human Perception and Performance, 18, 485-502.

Blumstein, S. E., Milberg, W. P., Dworetzky, B., Rosen, A., \& Gershberg, F. 1991. Syntactic priming effects in aphasia: An investigation of local syntactic dependencies. Brain and Language, 40, 393-421. 
Blumstein, S. E., Milberg, W., \& Shrier, R. 1982. Semantic processing in aphasia: Evidence from an auditory lexical decision task. Brain and Language, 17, 301-315.

Brown, C., \& Hagoort, P. 1993. The processing nature of the N400: Evidence from masked priming. Journal of Cognitive Neuroscience, 5, 34-44.

Carr, T. H., \& Dagenbach, D. 1990. Semantic priming and repetition priming from masked words: Evidence for a center-surround attentional mechanism in perceptual recognition. Journal of Experimental Psychology: Learning, Memory, and Cognition, 16, 341-350.

Chenery, H. J., Ingram, J. C. L., \& Murdoch, B. E. 1990. Automatic and volitional semantic processing in aphasia. Brain and Language, 38, 215-232.

Collins A. M., \& Loftus, E. F. 1975. A spreading-activation theory of semantic processing. Psychological Review, 82, 407-428.

De Groot, A. M. B. 1980. Mondelinge woordassociatienormen: 100 woordassociaties op 460 Nederlandse zelfstandige naamwoorden. Lisse, The Netherlands: Swets \& Zeitlinger.

De Groot, A. M. B. 1983. The range of automatic spreading activation in word priming. Journal of Verbal Learning and Verbal Behavior, 22, 417-436.

De Groot, A. M. B. 1984. Primed lexical decision: Combined effects of the proportion of related prime-target pairs and the stimulus-onset asynchrony of prime and target. The Quarterly Journal of Experimental Psychology A, 36, 253-280.

De Groot, A. M. B., Thomassen, A. J. W. M., \& Hudson, P. T. W. 1986. Primed lexical decision: The effect of varying the stimulus-onset asynchrony of prime and target. Acta Psychologica, 61, 17-36.

Friedman, R. B., Glosser, G., \& Diamond, H. 1988. Semantic versus associative lexical priming in Alzheimer's disease and fluent aphasia. Paper presented at the Annual Meeting of the Academy of Aphasia. Montreal, Canada.

Goodglass, H., \& Baker, E. 1976. Semantic field, naming, and auditory comprehension in aphasia. Brain and Language, 3, 359-374.

Graetz, P., de Bleser, R., Willmes, K., \& Heeschen, C. 1991. De Akense afasie test: Constructie van de Nederlandstalige versie. Logopedie en Foniatrie, 63, 58-68.

Graf, P., \& Mandler, G. 1984. Activation makes words more accessible, but not necessarily more retrievable. Journal of Verbal Learning and Verbal Behavior, 23, 553-568.

Grober, E., Perecman, E., Kellar, L., \& Brown, J. 1980. Lexical knowledge in anterior and posterior aphasics. Brain and Language, 10, 318-330.

Haarmann, H. J., \& Kolk, H. H. J. 1991. Syntactic priming in Broca's aphasics: Evidence of slow activation. Aphasiology, 5, 1-36.

Hagoort, P. 1989. Processing of Lexical ambiguities: A comment on Milberg, Blumstein, and Dworetzky (1987). Brain and Language, 36, 335-348.

Hagoort, P. 1990. Tracking the time course of language understanding in aphasia. Published doctoral dissertation, Nijmegen University.

Hagoort, P. 1993. Impairments of lexical-semantic processing in aphasia: Evidence from the processing of lexical ambiguities. Brain and Language, 45, 189-232.

Henderson, L. 1982. Orthography and word recognition in reading. London: Academic Press.

Just, M. A., \& Carpenter, P. A. 1992. A capacity theory of comprehension: Individual differences in working memory. Psychological Review, 99, 122-149.

Katz, W. F. 1988. An investigation of lexical ambiguity in Broca's aphasics using an auditory lexical priming technique. Neuropsychologia, 26, 747-752.

Keefe, D. E., \& Neely, J. H. 1990. Semantic priming in the pronunciation task: The role of prospective prime-generated expectancies. Memory \& Cognition, 18, 289-298.

Marslen-Wilson, W. 1984. Function and process in spoken word-recognition. In H. Bouma \& D. G. Bouwhuis (Eds.), Attention and performance X: Control of language processes. Hillsdale, NJ: Erlbaum.

Milberg, W., \& Blumstein, S. E. 1981. Lexical decision and aphasia: Evidence for semantic processing. Brain and Language, 14, 371-385.

Milberg, W., Blumstein, S. E., \& Dworetzky, B. 1987. Processing of lexical ambiguities in aphasia. Brain and Language, 31, 138-150. 
Milberg, W., Blumstein, S. E., \& Dworetzky, B. 1988. Phonological processing and lexical access in aphasia. Brain and Language, 34, 279-293.

Milberg, W., Blumstein, S. E., Katz, D., Gershberg, F., \& Brown, T. 1995. Semantic facilitation in aphasia: Effects of time and expectancy. Journal of Cognitive Neuroscience, 7, 33-50.

Neely, J. H. 1977. Semantic priming and retrieval from lexical memory: Roles of inhibitionless spreading activation and limited-capacity attention. Journal of Experimental Psychology: General, 106, 226-254.

Neely, J. H. 1991. Semantic priming effects in visual word recognition: A selective review of current findings and theories. In D. Besner \& G. Humphreys (Eds.), Basic processes in reading: Visual word recognition. Hillsdale, $\mathrm{NJ}$ : Erlbaum.

Neely, J. H., \& Keefe, D. E. 1989. Semantic context effects on visual word processing: A hybrid prospective/retrospective processing theory. In G. H. Bower (Ed.). The psychology of learning and motivation: Advances in research and theory (Vol. 24). New York: Academic Press.

Neely, J. H., Keefe, D. E., \& Ross, K. L. 1989. Semantic priming in the lexical decision task: Roles of prospective prime-generated expectancies and retrospective semantic matching. Journal of Experimental Psychology: Learning, Memory, and Cognition, 15, 1003-1019.

Ostrin, R. K., \& Tyler, L. K. 1993. Automatic access to lexical semantics in aphasia: Evidence from semantic and associative priming. Brain and Language, 45, 147-159.

Petersen, S. E., \& Fiez, J. A. 1993. The processing of single words studied with positron emission tomography. Annual Review of the Neurosciences, 16, 509-530.

Prather, P., Zurif, E., Stern, C., \& Rosen, T. J. 1992. Slowed lexical access in nonfluent aphasia: A case study. Brain and Language, 43, 336-348.

Seidenberg, M. S., Waters, G. S., Sanders, M., \& Langer, P. 1984. Pre- and postlexical loci of contextual effects on word recognition. Memory \& Cognition, 12, 315-328.

Shelton, J. R., \& Martin, R. C. 1992. How semantic is automatic semantic priming? Journal of Experimental Psychology: Learning, Memory, and Cognition, 18, 1191-1210.

Swaab, T., Brown, C., \& Hagoort, P. 1995. Delayed integration of lexical ambiguities in Broca's aphasics: Evidence from event-related potentials. Brain and Language, 51, 159161.

Tyler, L. K., Ostrin, R., Cooke, M., \& Moss, H. E. 1995. Automatic access of lexical information in Broca's aphasics: Against the automaticity hypothesis. Brain and Language, 48, $131-162$.

Uit den Boogaart, P. C. 1975. Woordfrequenties in geschreven en gesproken Nederlands. Oosthoek, The Netherlands: Scheltema \& Holkema.

Whitehouse, P., Caramazza, A., \& Zurif, E. 1978. Naming in aphasia: Interactivity effects of form and function. Brain and Language, 6, 63-74.

Zurif, E. B., Caramazza, A., Myerson, R., \& Galvin, J. 1974. Semantic feature representations for normal and aphasic language. Brain and Language, 1, 167-187. 